\title{
Enhancing the Voltage Stability of the Nigerian 330KV 48-Bus Power System Network Using Modal/Eigenvalue Analysis
}

\author{
Ezekiel Aneke* \\ Electrical and Electronics Engineering Department, Enugu State University of Science and Technology, \\ Agbani, Enugu, PMB 01660 Nigeria \\ Engla Anzaku. \\ Electrical and Electronics Engineering Department, Federal University of Agriculture, \\ Markurdi, Nigeria
}

\begin{abstract}
This study is based on the application of modal analysis on the 48 bus 330KV Nigerian Network using PSAT MATLAB Toolbox. The Modal/Eigenvalue analysis technique was used to investigate the stability of the 48-bus Nigerian power network system. The modal method calculates the smallest eigenvalue and all the associated eigenvectors of the Jacobian matrix using the steady state mode. The magnitude of the smallest eigenvalue estimates the proximity of the system to the voltage instability. The participation factor can be employed to identify the bus that provides the highest contribution to the instability of the system. The 48-bus Nigerian network was simulated under static loads and changing loads and Modal/Eigenvalue analysis was performed on the system under each of these conditions. It was found that increase in loads at the three selected weakest buses reduced the stability of the system. Results obtained in this study proved that reactive power compensators were able to drastically improve the stability profile of the 48 bus Nigerian network and even rescue the system at the event of voltage instability especially the ones caused by change in loads.
\end{abstract}

Keywords: Modal, voltage stability, eigenvalue, participation factors. MATLAB Toolbox, PSAT

DOI: $10.7176 /$ JIEA/9-7-04

Publication date: December $31^{\text {st }} 2019$

\section{INTRODUCTION}

Electric power supply plays a key role in the development and technological advancement of a nation. The need for steady and adequate supply of electrical power in Nigeria has risen tremendously, partly due to increase in population, industrial activities and increase in the use of electrical powered gadgets. In order to meet this challenge, systematic power system networks have been developed and are being modified on a continuous basis.

The grid system is usually the platform that provides interconnection of network of transmission lines that connects electrical power generating systems to load in a pattern of expanded integrated system that covers an entire country. Due to proximity of fuel for and other requirement for generation, generating stations are usually situated thousands of kilometers from one another and function in pairs. The power obtained from generating stations uses the grid system to transmit energy to load centers so that electrical energy can be accessible to consumers/customers.

Usually, there are always difficulties in the planning, operation, formation and co-ordination of a dense interconnection of national electric power system networks. Adequate knowledge and engineering skills and experience are required to properly handle these challenges adequately.

The stability of power system is a principal factor in power system network. Variation in load can generate a small but significant disturbance in a power network. Faults can also generate bigger proportion of disturbance to a power network causing variation in the power flow swing of the system. A stable power swing means the swiftness of the system to restore synchronous operation after a disturbance incidence on the system. Alternatively, a system that has unstable power swing may result in the alteration of synchronization with sets of machines functioning at a different synchronous speed [7]. One of the several problems facing the efficient performance of an interconnected system is voltage stability [3]. For the Nigerian power systems, evaluation of voltage stability and forecast of voltage instability assessment is executed as an aspect of system scheduling, operational planning and real-time control. The Nigerian national grid suffers from serious cases of voltage instability or voltage collapse in a frequent manner which greatly affects the socio-economic activities of the Nation [2].

Considering this situation, there is a need to explore an analytical approach, which can envisage the voltage collapse problem in a power system. Consequently, significant consideration has been given to this challenge by several power system scholars. The dynamic analysis is chiefly vital in the last stages of the voltage collapse. Dynamic voltage stability is evaluated by observing the eigen-value of the linearized system as a power system is increasingly loaded. Instability occurs when a pair of complex eigen-value crosses to the right half plane. This system represents the dynamic voltage instability [3].

This paper uses the MATLAB software environment to model an interconnected power system networks 
using power system analysis toolsbox (PSAT) and simulated for voltage stability evaluation using Modal Analysis Technique, and also simulation of the solution to the instability due to load by using Static Var Systems was done. The method of improvement of voltage stability used by this thesis is the enhancement of a method to recalculate the out-of-step protection settings to suit the prevalent operating condition of some of the generators of the Nigeria 48 bus power system network.

\subsection{REVIEW OF PREVIOUS STUDIES}

In the past three decades, intense efforts have been geared towards analyzing and solving the problem of voltage stability in power system network. Different methods have been used to analyze, predict, identify and find solution to voltage instability and collapse. Newton based algorithms have a problem in handling a large number of inequality constraints. Linear programming methods are fast and reliable, but the main disadvantage is associated with the piecewise linear cost approximation. Nonlinear programming methods have a difficulty of convergence and algorithm complexity.

[5] Proposed analysis and the use of modal based method in the estimation of voltage stability of bulk power system and utilize the power system Jacobian matrix to calculate the eigenvalues required for the analysis of the voltage stability of the power system network. This method employs the negative or positive eigenvalues state to rate the stability of the system. This method was used to determine the components of the system that contribute to instability through the use of the participating factors. The method was implemented on IEEE 14 bus system and the various eigenvalues were calculated and the one with the lowest magnitude value used to estimate the participation factors that indicate buses that will contribute highest to voltage instability of the system.

Theoretically and in practice there are several mathematical methods to optimize the distribution of the generated power dispatching. The application of the artificial intelligence has proved its efficacy when applied to the optimization of objective functions [4].

[5] Carried out a research on voltage stability evaluation for system collapse improvement in Nigeria Electric Power System (NEPS) reduced to 33 bus systems using modal analysis. The Q-V curves were computed for the weakest buses of this identified critical mode in the NEPS reduce to 33 Bus systems as supported and compared with the results obtained by modal analyses technique.

[6] Proposed modelling and simulations of steady-state stability problems in MATLAB environment are performed using author developed computational tool implementing both conventional and more advanced numerical approaches. The performance obtain was compared with the Simulink-based library Power System Analysis Toolbox (PSAT) in terms of solution accuracy, CPU time and possible limitations.

\section{THE POWER FLOW PROBLEM AND MODAL ANALYSIS}

\subsection{Power Flow Problem Formulation}

Power flow analysis is essential in the coordination of power system to guarantee that power systems are run properly. One advantage of the Newton-Raphson method (NR) is the speed of convergence especially in very large power system networks. Another factor that makes Newton-Raphson method powerful is the adaptability of this method in most power system modelling software like MATLAB. The power flow equation is derived in polar form because in the power flow problem analysis, real power and voltage magnitude are stated for the voltagecontrolled buses (Samuel et al., 2014).

The expression for current flow in a power system network in polar form is given as [4]

$I_{i}=\sum_{j=1}^{n}\left|Y_{i j}\right|\left|V_{i}\right| \angle\left(\theta_{i j}+\delta_{j}\right)$

To determine the real power at a given bus $i$ is

$P_{i}=V^{*} I_{i}+j Q_{i}$

Equation 2 can be rearranged in polar form using equation 1 as

$P_{i}=\left|V_{i}\right| \angle\left(-\delta_{i}\right) \sum_{j=1}^{n}\left|Y_{i j}\right|\left|V_{i}\right| \angle\left(\theta_{i j}+\delta_{j}\right)+j Q_{i}$

Equation 3 can be separated- the real and the imaginary portion for easy estimation in a network and are obtained in Equation 4 and 5 respectively.

$P_{i}=\sum_{j=1}^{n}\left|Y_{i j}\right|\left|V_{i}\right|\left|V_{j}\right| \cos \left(\theta_{i j}+\delta_{j}-\delta_{i}\right)$

$Q_{i}=-\sum_{j=1}^{n}\left|Y_{i j}\right|\left|V_{i}\right|\left|V_{j}\right| \sin \left(\theta_{i j}+\delta_{j}-\delta_{i}\right)$

The real and the reactive component of the power in equations (4) and (5) can be expanded using Taylor series to produce a pattern of linear equations involving a Jacobian matrix which exhibits clear link relating small variation real power with voltage angle and also the variation of voltage magnitude with variation in reactive power. This can be simplified as

$\left[\begin{array}{l}\Delta P \\ \Delta Q\end{array}\right]=\left[\begin{array}{ll}J_{1} & J_{2} \\ J_{3} & J_{4}\end{array}\right]\left[\begin{array}{c}\Delta \delta \\ |\Delta V|\end{array}\right]$

$\Delta \mathrm{P}$ and $\Delta \mathrm{Q}$ represent differences between specified values and calculated values respectively, $\Delta \mathrm{V}$ and $\Delta \delta$ represent voltage magnitude and voltage angle respectively in incremental forms and sub-matrices $\mathrm{J}_{1}$ through $\mathrm{J}_{4}$ 
form the Jacobian matrix [5].

\subsection{Modal Analysis}

The modal (eigenvalue) analysis can be used essentially as a formidable analytical tool to investigate both proximity and mechanism of voltage instability [3]. The process of voltage collapse is a dynamic occurrence, but static power network solution methods can still be utilized to generate criteria which are good markers of voltage stability margin and can ascertain weak buses of the system.

Modal analysis method is capable of calculating voltage collapse or instability in power system networks. The major aspect of this technique involves the estimation of the smallest eigenvalues and related eigenvectors of the reduced Jacobian matrix acquired from performing load flow analysis. Eigenvalues have a great deal of relationship with the mode of voltage and reactive power variation, and are employed to estimate voltage instability in a power network system. After execution of modal analysis, the participation factors are usually utilized to easily identify the weakest connections or buses in the system. The participation factor values can adequately be used to determine the weakest bus in the system. The participation factor values are usually obtained from the eigen-vectors analysis of eigenvalues.

Modal analysis $\Delta \mathrm{V} / \Delta \mathrm{Q}$ is an important method for forecasting voltage collapse and determination of the stability margin in power system. By solving linearized power flow equation, the $\Delta \mathrm{P}$ and $\Delta \mathrm{Q}$ matrix is obtained in equation 6 from the previous power flow solution [4].

$\left[\begin{array}{l}\Delta P \\ \Delta Q\end{array}\right]=\left[\begin{array}{ll}J_{1} & J_{2} \\ J_{3} & J_{4}\end{array}\right]\left[\begin{array}{c}\Delta \theta \\ |\Delta V|\end{array}\right]$

Considering $P \Delta=0$, the reduced Jacobian matrix as obtained in equation 7 is expressed as:

$\Delta J_{L}=\left[J_{4}-J_{3} J_{1}^{-1} J_{2}\right]$

$\Delta Q=J_{L} \Delta V$

$\Delta V=J_{L}^{-1} \Delta Q$

Putting

$J_{L}=\xi \Lambda \eta$

where

$\xi$ is right eigenvector matrix

$\eta$ is left eigenvector matrix

$\Lambda$ is diagonal eigenvalue matrix

Then, inverting equation 11 produces

$J_{L}^{-1}=\xi \Lambda^{-1} \eta$

And substituting equation 12 in equation 11 gives

$\Delta V=\xi \Lambda^{-1} \eta \Delta Q$

$\Delta V=\sum_{i} \frac{\xi_{i} \eta_{i}}{\delta_{i}} \Delta Q$

where $\eta_{\mathrm{i}}$ is the ith row of the left eigenvector of $J R$, and $\xi_{\mathrm{i}}$ is the $\mathrm{i}^{\text {th }}$ column of the right eigenvector. The $\mathrm{i}^{\text {th }}$ mode of the $\mathrm{Q}-\mathrm{V}$ response is defined by the $\mathrm{i}^{\text {th }}$ eigenvalue $\delta_{\mathrm{i}}$, and the corresponding right and left eigenvectors $\xi_{\mathrm{i}}$ and $\eta_{\mathrm{i}}$. Equation (13) can be presented as

$\eta \Delta V=\Lambda^{-1} \eta \Delta Q$

By defining $v=\Lambda^{-\mathrm{q}}$ as the vector of modal voltage changes and as the vector of modal reactive power changes, the first-order equations can be broken down as

$v=\Lambda^{-1} q$

Therefore, for the $\mathrm{i}^{\text {th }}$ mode, we have

$v_{i}=\frac{1}{\delta_{i}} q_{i}$

At the instant where $\delta_{\mathrm{i}}>0$, the $\mathrm{i}^{\text {th }}$ modal voltage and the $\mathrm{i}^{\text {th }}$ modal reactive power changes align in the same direction, indicating voltage stability of the system; whereas $\delta_{\mathrm{i}}<0$ denotes the instability of the system. The magnitude of $\delta_{i}$ signifies an average level of instability of the $i^{\text {th }}$ modal voltage. The smaller the magnitude of a positive $\delta_{\mathrm{i}}$, the nearer the $\mathrm{i}^{\text {th }}$ modal voltage to experience instability. The system voltage collapse when $\delta_{\mathrm{i}}=0$, and is as a result of changes in the modal reactive power that causes an infinite change in the modal voltage.

A system voltage is assumed to be stable if the eigenvalues of $J_{R}$ are all positive. However, in the analysis of dynamic systems the eigenvalues with negative real parts are stable. The interaction between system voltage stability and eigenvalues of the $J_{R}$ matrix is best understood by relating the eigenvalues with the V-Q sensitivities of each bus (which must be positive for stability). $\mathrm{J}_{\mathrm{R}}$ can be taken as a symmetric matrix and therefore the eigenvalues of $J_{R}$ are close to being purely real. If all the eigenvalues are positive, $J_{R}$ is positive definite and the $\mathrm{V}-\mathrm{Q}$ sensitivities are also positive, indicating that the system is voltage stable. The system is considered voltage unstable if one or more of the eigenvalues is found to be negative. A zero eigenvalue of $J_{R}$ means that the system is on the point of voltage instability. In essence, small eigenvalue of $J_{R}$ determines the proximity of the system to 
being voltage unstable [4]. There is no need to evaluate all the eigenvalues of JR of a large power system because it is known that once the minimum eigenvalues become zero the system Jacobian matrix becomes singular and voltage instability occurs. Therefore, the eigenvalues that are vital are the critical eigenvalues of the reduced Jacobian matrix $J_{R}$. This implies that the smallest eigenvalues of $J_{R}$ are taken to be the least stable nodes of the system. The rest of the eigenvalues are not considered because these nodes are considered to be vital in the determination of stability of the system. After the minimum eigenvalues and the corresponding eigenvectors have been calculated the participation factor can be utilized to identify the weakest bus in the system.

The relative contribution of the power at bus $\mathrm{k}$ in mode $\mathrm{i}$ is given by the bus participation factor [3]

$P_{k i}=\xi_{k i} \eta_{k i}$

Participation factors show the most critical nodes which can lead the system to instability. Generally, the higher the magnitude of the participation factor of a bus in a specific mode, the easier the solution that can be applied on that bus in stabilizing the node.

The flowchart developed for outlining the steps followed in the modal/eigenvalue analysis of the power system network is shown in Figure 1 below.

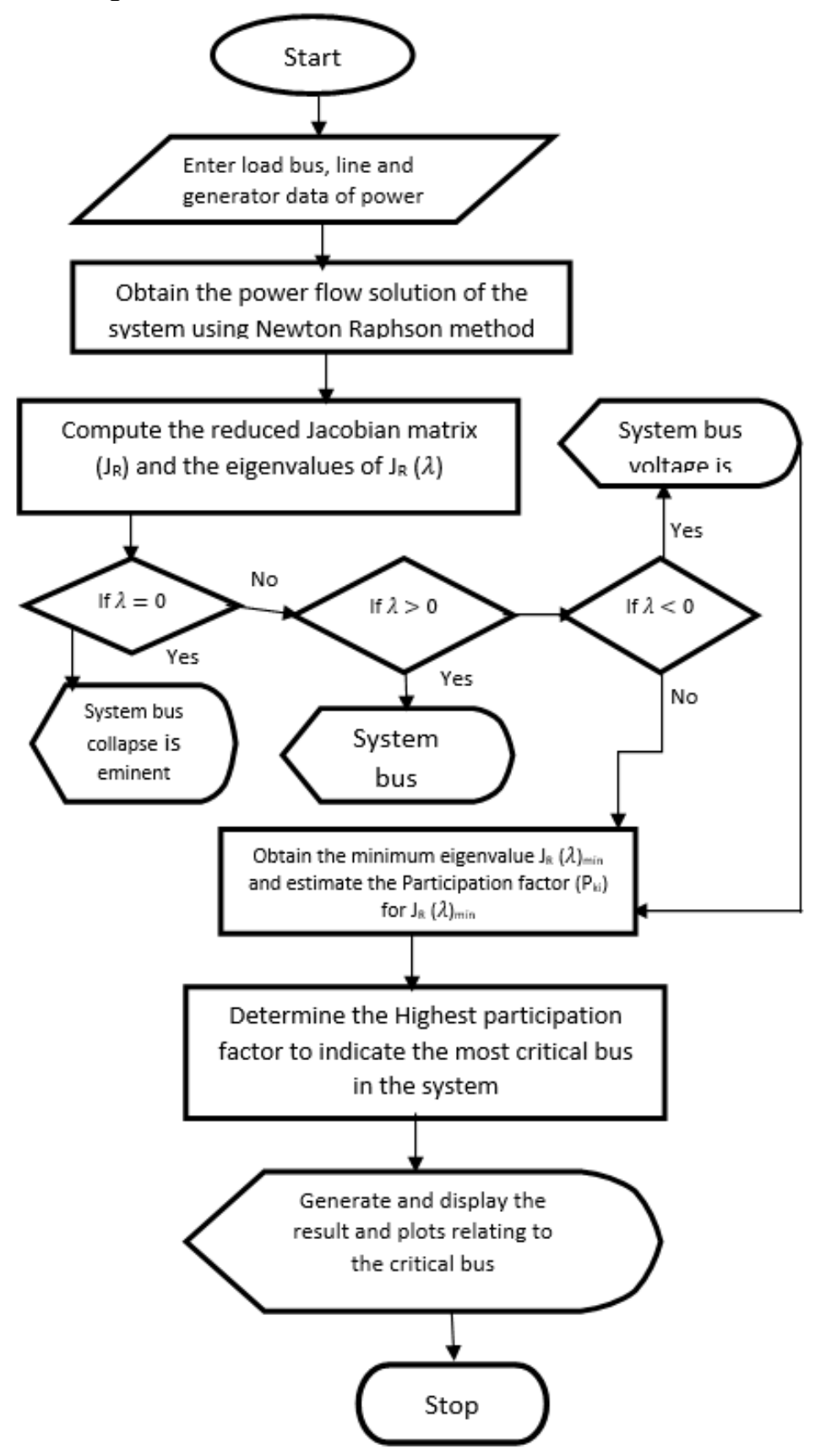

Figure 1: Algorithm for the modal analysis method of stability analysis (Courtesy of Modern power system Analysis by D.P.Kothari and I.J. Nagrath) 


\subsection{The 330KV 48-Bus Nigerian Power System Network and Data}

The Nigerian 48 bus power system network configuration and one-line diagram is depicted as shown in Figure 2. For the study of the system to be actualized 330KV 48 bus system of Nigeria transmission network, the Egbin power station was selected as the slack bus. Data gathering from TCN were centred on 2018 operational reports. Line data, load data, the generators and other system constituents were also collated and assembled.

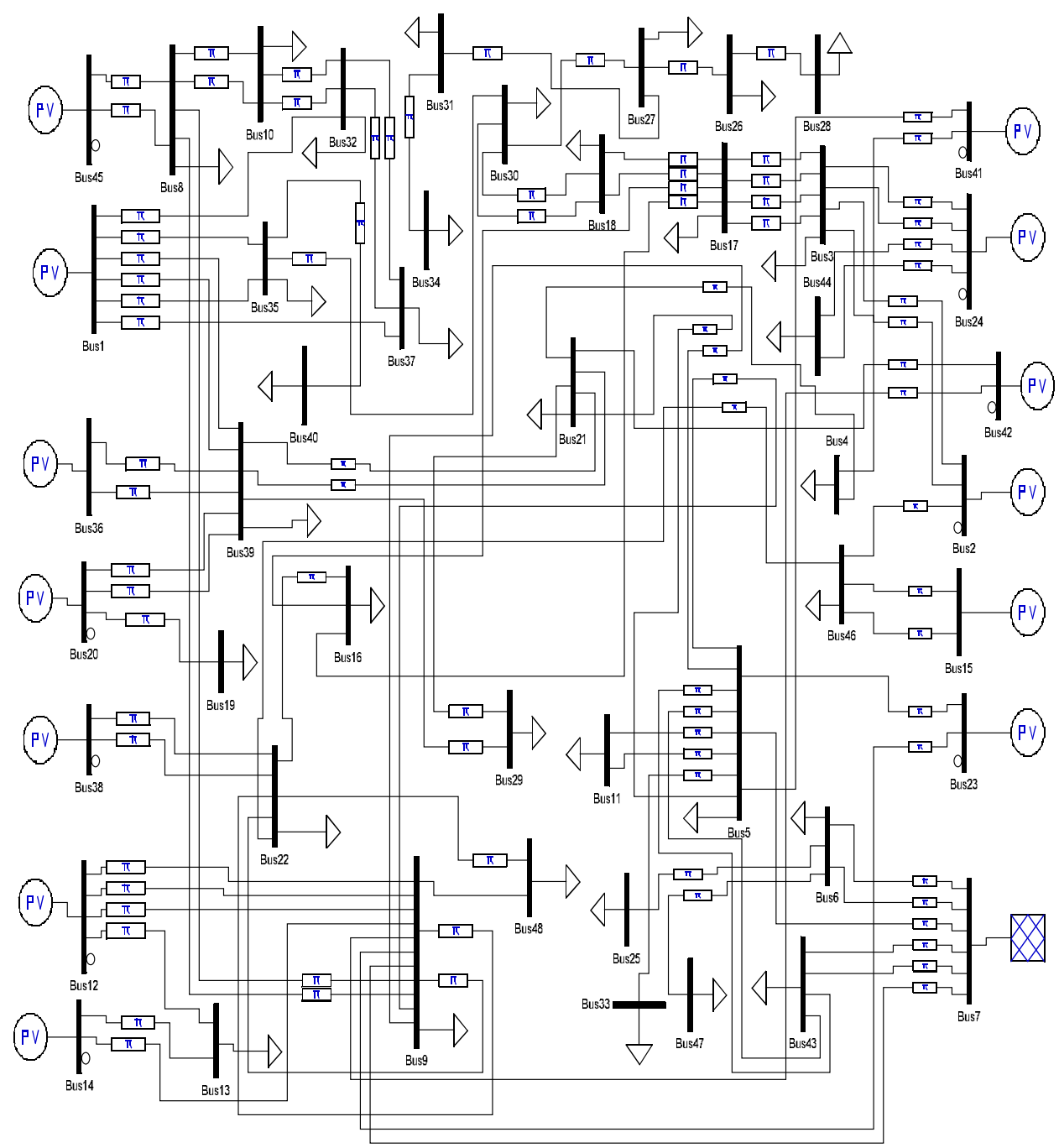

Figure 2: Main Model of the Nigerian 48-bus 330KV Power System Network using PSAT.

The data for the power flow analysis and modal analysis involves the bus data, transmission line data (impedance of lines), voltages and transformer/load data obtained from Transmission Company of Nigeria (TCN) are as presented in Tables 1 to 2 respectively. 
Table 1: System Bus data of the 330kV, 48-bus Network (Source: Transmission Company of Nigeria, 2018)

\begin{tabular}{|c|c|c|c|c|c|c|c|c|c|c|}
\hline \multirow[t]{2}{*}{ S/No } & \multirow[t]{2}{*}{ Bus Name } & \multirow{2}{*}{$\begin{array}{l}\text { Volts } \\
\text { Mag. } \\
\text { (p.u.) }\end{array}$} & \multirow{2}{*}{$\begin{array}{l}\text { Angle } \\
\text { (Deg.) }\end{array}$} & \multirow{2}{*}{$\begin{array}{c}\text { Bus } \\
\text { Type/ } \\
\text { Code }\end{array}$} & \multicolumn{2}{|c|}{ Bus Loads } & \multicolumn{4}{|c|}{ Generation } \\
\hline & & & & & $\begin{array}{c}\mathbf{P} \\
(\mathbf{M W})\end{array}$ & $\begin{array}{c}\mathbf{Q} \\
\text { (Mvar) }\end{array}$ & $\begin{array}{c}\mathbf{P} \\
(\mathbf{M W})\end{array}$ & $\begin{array}{c}\mathbf{Q} \\
\text { (Mvar) }\end{array}$ & $\mathbf{Q}_{\min }$ & $\mathbf{Q}_{\max }$ \\
\hline 1 & Shiroro G/S & 1.000 & 0 & $\mathrm{P}-\mathrm{V}(2)$ & 150 & 70 & 270 & 220 & -200 & 200 \\
\hline 2 & Afam G/S & 1.000 & 0 & P-V (2) & 315 & 157.5 & 650 & 590 & -210 & 222 \\
\hline 3 & Ikot Ekpene & 1.020 & 0 & P-Q (3) & 321 & 160.5 & 0 & 0 & 0 & 0 \\
\hline 4 & Ayede & 0.932 & 0 & P-Q (3) & 275 & 206 & 0 & 0 & 0 & 0 \\
\hline 5 & Ikeja West & 0.986 & 0 & P-Q (3) & 635 & 474 & 0 & 0 & -150 & 0 \\
\hline 6 & Aja & 1.040 & 0 & P-Q (3) & 300 & 205 & 0 & 0 & 0 & 0 \\
\hline 7 & Egbin $\mathrm{G} / \mathrm{S}$ & 1.050 & 0 & Slack (1) & 0 & 0 & 0 & 0 & -200 & 210 \\
\hline 8 & Ajaokuta & 1.026 & 0 & P-Q (3) & 230 & 115 & 0 & 0 & 0 & 0 \\
\hline 9 & Benin & 1.000 & 0 & P-Q (3) & 383 & 150 & 0 & 0 & -150 & 0 \\
\hline 10 & Lokoja & 1.020 & 0 & $\mathrm{P}-\mathrm{Q}(3)$ & 300 & 150 & 0 & 0 & 0 & 0 \\
\hline 11 & Akangba & 0.970 & 0 & P-Q (3) & 300 & 250 & 0 & 0 & 0 & 0 \\
\hline 12 & Sapele G/S & 0.979 & 0 & $\mathrm{P}-\mathrm{V}(2)$ & 120 & 50 & 160 & 90 & -180 & 200 \\
\hline 13 & Aladja & 1.046 & 0 & P-Q (3) & 100 & 70 & 0 & 0 & 0 & 0 \\
\hline 14 & Delta G/S & 1.050 & 0 & $\mathrm{P}-\mathrm{V}(2)$ & 107 & 53 & 460 & 250 & -100 & 120 \\
\hline 15 & Alaoji G/S & 1.010 & 0 & $\mathrm{P}-\mathrm{V}(2)$ & 65 & 33 & 120 & 95 & -75 & 80 \\
\hline 16 & New Haven & 1.050 & 0 & P-Q (3) & 180 & 130 & 0 & 0 & 0 & 0 \\
\hline 17 & Ugwuaji & 1.097 & 0 & P-Q (3) & 39 & 25 & 0 & 0 & 0 & 0 \\
\hline 18 & Makurdi & 1.060 & 0 & P-Q (3) & 84 & 50 & 0 & 0 & -75 & 0 \\
\hline 19 & Birnin Kebbi & 1.010 & 0 & P-Q (3) & 146 & 85 & 0 & 0 & 0 & 0 \\
\hline 20 & Kainji G/S & 1.050 & 0 & $\mathrm{P}-\mathrm{V}(2)$ & 7 & 5 & 282 & -65 & -180 & 200 \\
\hline 21 & Osogbo & 0.966 & 0 & $\mathrm{P}-\mathrm{Q}(3)$ & 200 & 150 & 0 & 0 & -75 & 0 \\
\hline 22 & Onitsha & 1.005 & 0 & P-Q (3) & 184 & 134 & 0 & 0 & -75 & 0 \\
\hline 23 & Omotosho G/S & 1.050 & 0 & $\mathrm{P}-\mathrm{V}(2)$ & 18 & 15 & 664 & 300 & -150 & 150 \\
\hline 24 & $\begin{array}{l}\text { Odukpani } \quad \text { G/S } \\
\text { (Calabar) }\end{array}$ & 1.058 & 0 & P-V (2) & 10 & 7 & 240 & 150 & -120 & 200 \\
\hline 25 & Alagbon & 1.000 & 0 & $\mathrm{P}-\mathrm{Q}(3)$ & 260 & 120 & 0 & 0 & 0 & 0 \\
\hline 26 & Damaturu & 1.050 & 0 & P-Q (3) & 50 & 20 & 0 & 0 & 0 & 0 \\
\hline 27 & Gombe & 1.045 & 0 & P-Q (3) & 320 & 170 & 0 & 0 & -100 & 100 \\
\hline 28 & Maidugiri & 0.996 & 0 & $\mathrm{P}-\mathrm{Q}(3)$ & 10 & 5 & 0 & 0 & 0 & 0 \\
\hline 29 & Ganmo & 1.073 & 0 & P-Q (3) & 150 & 90 & 0 & 0 & 0 & 0 \\
\hline 30 & Jos & 0.970 & 0 & P-Q (3) & 70 & 50 & 0 & 0 & -75 & 0 \\
\hline 31 & Yola & 1.087 & 0 & P-Q (3) & 100 & 50 & 0 & 0 & -75 & 0 \\
\hline 32 & Gwagwalada & 1.060 & 0 & P-Q (3) & 150 & 70 & 0 & 0 & 0 & 0 \\
\hline 33 & Sakete & 1.003 & 0 & $\mathrm{P}-\mathrm{Q}(3)$ & 50 & 20 & 0 & 0 & 0 & 0 \\
\hline 34 & Jalingo & 1.007 & 0 & P-Q (3) & 80 & 50 & 0 & 0 & 0 & 0 \\
\hline 35 & Mando (Kaduna) & 1.040 & 0 & P-Q (3) & 170 & 120 & 0 & 0 & -75 & 0 \\
\hline 36 & Jebba G/S & 1.065 & 0 & $\mathrm{P}-\mathrm{V}(2)$ & 20 & 0 & 360 & 160 & -110 & 150 \\
\hline 37 & Katampe (Abuja) & 1.000 & 0 & P-Q (3) & 290 & 145 & 0 & 0 & -75 & 0 \\
\hline 38 & Okpai G/S & 1.000 & 0 & P-V (2) & 10 & 5 & 450 & 150 & -150 & 190 \\
\hline 39 & Jebba & 1.040 & 0 & P-Q (3) & 15 & 5 & 0 & 0 & -150 & 0 \\
\hline 40 & $\begin{array}{l}\text { Kumbotso } \\
\text { (Kano) }\end{array}$ & 1.000 & 0 & P-Q (3) & 240 & 130 & 0 & 0 & -75 & 0 \\
\hline 41 & Olorunsogo $\mathrm{P} / \mathrm{S}$ & 1.020 & 0 & $\mathrm{P}-\mathrm{V}(2)$ & 20 & 10 & 626 & 300 & -150 & 150 \\
\hline 42 & Ihovbor G/S & 1.050 & 0 & $\mathrm{P}-\mathrm{V}(2)$ & 8 & 3 & 225 & 110 & -70 & 90 \\
\hline 43 & Okearo & 0.999 & 0 & P-Q (3) & 220 & 70 & 0 & 0 & -75 & 0 \\
\hline 44 & Adiabor & 0.905 & 0 & P-Q (3) & 140 & 90 & 0 & 0 & 0 & 0 \\
\hline 45 & Geregu G/S & 1.050 & 0 & $\mathrm{P}-\mathrm{V}(2)$ & 20 & 5 & 415 & 200 & -200 & 210 \\
\hline 46 & Alaoji & 1.010 & 0 & P-Q (3) & 400 & 150 & 0 & 0 & -75 & 0 \\
\hline 47 & Lekki & 1.000 & 0 & P-Q (3) & 10 & 2 & 0 & 0 & 0 & 0 \\
\hline 48 & Asaba & 0.998 & 0 & P-Q (3) & 2 & 0 & 0 & 0 & 0 & 0 \\
\hline
\end{tabular}


Table 2 System Line Data of 330kV, 48-bus Grid Network (Source: Transmission Company of Nigeria, 2018)

\begin{tabular}{|c|c|c|c|c|c|c|}
\hline \multirow{2}{*}{$\mathbf{S} / \mathbf{N}$} & \multirow{2}{*}{ CODE } & \multirow{2}{*}{$\begin{array}{l}\text { FROM (BUS NAME) / } \\
\text { TO (BUS NAME) }\end{array}$} & \multicolumn{2}{|c|}{ LINE IMPEDANCE } & \multirow{2}{*}{ 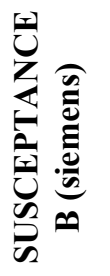 } & \multirow{2}{*}{$\begin{array}{c}\text { LINE } \\
\text { LENGTH } \\
\text { (KM) }\end{array}$} \\
\hline & & & $\mathbf{R}(\Omega)$ & $X(\Omega)$ & & \\
\hline 1 & K1J & Kainji/Jebba Line 1 & 3.159 & 26.811 & 0.0368 & 81 \\
\hline 2 & $\mathrm{~K} 2 \mathrm{~J}$ & Kainji/Jebba Line 2 & 3.159 & 26.811 & 0.0368 & 81 \\
\hline 3 & K3R & Kainji/Birnin Kebbi & 12.090 & 102.610 & 0.0096 & 310 \\
\hline 4 & $\mathrm{~B} 8 \mathrm{~J}$ & Jebba G.S/Jebba T.S 1 & 0.315 & 2.424 & 0.4057 & 8 \\
\hline 5 & B9J & Jebba G.S/Jebba T.S 2 & 0.315 & 2.424 & 0.4057 & 8 \\
\hline 6 & J3R & Jebba/Shiroro Line 1 & 9.516 & 80.764 & 0.0122 & 244 \\
\hline 7 & $\mathrm{~J} 7 \mathrm{R}$ & Jebba/Shiroro Line 2 & 9.516 & 80.764 & 0.0122 & 244 \\
\hline 8 & $\mathrm{~J} 1 \mathrm{H}$ & Jebba/Osogbo Line 1 & 6.123 & 51.967 & 0.0189 & 157 \\
\hline 9 & $\mathrm{~J} 2 \mathrm{H}$ & Jebba/Osogbo Line 2 & 6.123 & 51.967 & 0.0189 & 157 \\
\hline 10 & $\mathrm{~J} 3 \mathrm{G}$ & Jebba/Ganmo Line & 3.393 & 28.797 & 0.0342 & 87 \\
\hline 11 & $\mathrm{H} 3 \mathrm{G}$ & Osogbo/Ganmo & 2.730 & 23.170 & 0.0426 & 70 \\
\hline 12 & $\mathrm{H} 2 \mathrm{~A}$ & Osogbo/Ayede & 4.485 & 38.065 & 0.0259 & 115 \\
\hline 13 & $\mathrm{H} 1 \mathrm{~W}$ & Osogbo/Ikeja West & 9.828 & 83.412 & 0.0118 & 252 \\
\hline 14 & $\mathrm{H7V}$ & Osogbo/Ihovbor & 8.814 & 74.806 & 0.0132 & 226 \\
\hline 15 & V7B & Ihovbor/Benin & 0.195 & 1.655 & 0.5959 & 5 \\
\hline 16 & M2S & Mando/Jos & 7.683 & 65.207 & 0.0151 & 197 \\
\hline 17 & SIE & Jos/Gombe & 10.335 & 87.715 & 0.0112 & 265 \\
\hline 18 & M6N & Mando/Kumbotso & 8.970 & 76.130 & 0.0129 & 230 \\
\hline 19 & R1M & Shiroro/Mando Line 1 & 3.744 & 31.766 & 0.0310 & 96 \\
\hline 20 & $\mathrm{R} 2 \mathrm{M}$ & Shiroro/Mando Line 2 & 3.744 & 31.766 & 0.0310 & 96 \\
\hline 21 & R4B & Shiroro/Katampe Line 1 & 5.674 & 43.632 & 0.0225 & 144 \\
\hline 22 & R5G & Shiroro/Gwagwalada & 4.680 & 39.720 & 0.0248 & 120 \\
\hline 23 & G5B & Gwagwalada/Katampe & 1.560 & 13.240 & 0.0745 & 40 \\
\hline 24 & N6W & Egbin/Ikeja West Line 3 & 2.443 & 18.786 & 0.0523 & 62 \\
\hline 25 & $\mathrm{~N} 7 \mathrm{~K}$ & Egbin/Okearo Line 1 & 2.176 & 18.469 & 0.0534 & 55.8 \\
\hline 26 & N8K & Egbin/Okearo Line 2 & 2.176 & 18.469 & 0.0534 & 55.8 \\
\hline 27 & K7W & Okearo /Ikeja West Line 1 & 1.088 & 9.235 & 0.1068 & 27.9 \\
\hline 28 & K8W & Okearo/ Ikeja West Line 2 & 1.088 & 9.235 & 0.1068 & 27.9 \\
\hline 29 & W3L & Ikeja West/Akangba 1 & 0.6762 & 5.739 & 0.1719 & 17.34 \\
\hline 30 & W4L & Ikeja West/Akangba 2 & 0.6762 & 5.739 & 0.1719 & 17.34 \\
\hline 31 & M5W & Omotosho/Ikeja West & 6.304 & 48.480 & 0.0203 & 160 \\
\hline 32 & R1W & Olorunsogo/Ikeja West & 3.034 & 23.331 & 0.0421 & 77 \\
\hline 33 & NW1BS & Ikeja West/Sakete & 2.730 & 23.170 & 0.0426 & 70 \\
\hline 34 & $\mathrm{R} 2 \mathrm{~A}$ & Olorunsogo/Ayede & 2.340 & 19.860 & 0.0497 & 60 \\
\hline 35 & B6N & Benin/Egbin & 8.502 & 72.158 & 0.0137 & 218 \\
\hline 36 & $\mathrm{~B} 11 \mathrm{~J}$ & Benin/Ajaokuta Line 1 & 7.995 & 67.855 & 0.0145 & 205 \\
\hline 37 & $\mathrm{~B} 12 \mathrm{~J}$ & Benin/Ajaokuta Line 2 & 7.995 & 67.855 & 0.0145 & 205 \\
\hline 38 & $\mathrm{~B} 1 \mathrm{~T}$ & Benin/Onitsha Line1 & 5.343 & 45.347 & 0.0217 & 137 \\
\hline 39 & $\mathrm{~B} 2 \mathrm{~T}$ & Benin/Onitsha Line2 & 5.343 & 45.347 & 0.0217 & 137 \\
\hline 40 & B5M & Benin/Omotosho G/S & 4.680 & 39.720 & 0.0248 & 120 \\
\hline 41 & S3B & Sapele/Benin Line 1 & 2.028 & 17.212 & 0.0573 & 52 \\
\hline 42 & S4B & Sapele/Benin Line 2 & 2.028 & 17.212 & 0.0573 & 52 \\
\hline 43 & S5B & Sapele/Benin Line 3 & 2.028 & 17.212 & 0.0573 & 52 \\
\hline 44 & S4W & Sapele/Aladja & 2.457 & 20.853 & 0.0473 & 63 \\
\hline 45 & R1J & Geregu/Ajaokuta line 1 & 0.195 & 1.655 & 0.5959 & 5 \\
\hline 46 & R2J & Geregu/Ajaokuta line 2 & 0.195 & 1.655 & 0.5959 & 5 \\
\hline 47 & G3B & Delta/Benin & 2.053 & 17.427 & 0.0566 & 52.65 \\
\hline 48 & $\mathrm{~T} 3 \mathrm{H}$ & Onitsha/New Haven & 3.744 & 31.776 & 0.0157 & 96 \\
\hline
\end{tabular}




\begin{tabular}{|c|c|c|c|c|c|c|}
\hline \multirow{2}{*}{$\mathbf{S} / \mathbf{N}$} & \multirow{2}{*}{ CODE } & \multirow{2}{*}{$\begin{array}{c}\text { FROM (BUS NAME) / } \\
\text { TO (BUS NAME) }\end{array}$} & \multicolumn{2}{|c|}{ PEDANCE } & \multirow{2}{*}{ 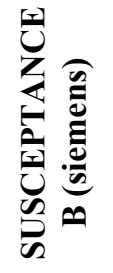 } & \multirow{2}{*}{$\begin{array}{c}\text { LINE } \\
\text { LENGTH } \\
(\text { KM) }\end{array}$} \\
\hline & & & $\mathbf{R}(\mathbf{\Omega})$ & $\mathbf{X}(\mathbf{\Omega})$ & & \\
\hline 49 & K1T & Okpai/Onitsha Line 1 & 2.184 & 18.536 & 0.0532 & 56 \\
\hline 50 & $\mathrm{~K} 2 \mathrm{~T}$ & Okpai/Onitsha Line 2 & 2.184 & 18.536 & 0.0532 & 56 \\
\hline 51 & T4A & Onitsha/Alaoji & 5.382 & 45.678 & 0.0216 & 138 \\
\hline 52 & F1A & Afam/Alaoji Line 1 & 1.123 & 9.533 & 0.1035 & 28.8 \\
\hline 53 & F2A & Afam/Alaoji Line 2 & 1.123 & 9.533 & 0.1035 & 28.8 \\
\hline 54 & N3J & Egbin/Aja Line 1 & 0.552 & 4.242 & 0.2318 & 14 \\
\hline 55 & $\mathrm{~N} 4 \mathrm{~J}$ & Egbin/Aja Line 2 & 0.552 & 4.242 & 0.2318 & 14 \\
\hline 56 & $\mathrm{~J} 1 \mathrm{~L}$ & Ajaokuta/Lokoja Line 1 & 1.482 & 12.578 & 0.0784 & 38 \\
\hline 57 & $\mathrm{~J} 2 \mathrm{~L}$ & Ajaokuta/Lokoja Line 2 & 1.482 & 12.578 & 0.0784 & 38 \\
\hline 58 & L6G & Lokoja/Gwagwalada line 1 & 6.240 & 52.960 & 0.0186 & 160 \\
\hline 59 & $\mathrm{~L} 7 \mathrm{G}$ & Lokoja/Gwagwalada line 2 & 6.240 & 52.960 & 0.0186 & 160 \\
\hline 60 & $\mathrm{H} 1 \mathrm{U}$ & New Haven/Ugwuaji line 1 & 0.273 & 2.317 & 0.4257 & 7 \\
\hline 61 & $\mathrm{H} 2 \mathrm{U}$ & New Haven/Ugwuaji line 2 & 0.273 & 2.317 & 0.4257 & 7 \\
\hline 62 & D1B & Odukpani/Adiabor line 1 & 0.690 & 5.859 & 0.1683 & 17.7 \\
\hline 63 & D2B & Odukpani/Adiabor line 2 & 0.690 & 5.859 & 0.1683 & 17.7 \\
\hline 64 & $\mathrm{~F} 1 \mathrm{E}$ & Afam/Ikot Ekpene line 1 & 2.457 & 20.853 & 0.0473 & 63 \\
\hline 65 & F2E & Afam/Ikot Ekpene line 2 & 2.457 & 20.853 & 0.0473 & 63 \\
\hline 66 & $\mathrm{~A} 1 \mathrm{~K}$ & Alaoji/Ikot Ekpene line 1 & 2.145 & 18.205 & 0.0542 & 55 \\
\hline 67 & $\mathrm{~A} 2 \mathrm{~K}$ & Alaoji/lkot Ekpene line 2 & 2.145 & 18.205 & 0.0542 & 55 \\
\hline 68 & $\mathrm{~K} 1 \mathrm{U}$ & Ikot Ekpene/Ugwuaji line 1 & 3.861 & 32.769 & 0.0301 & 99 \\
\hline 69 & $\mathrm{~K} 2 \mathrm{U}$ & Ikot Ekpene/Ugwuaji line 2 & 3.861 & 32.769 & 0.0301 & 99 \\
\hline 70 & $\mathrm{~K} 3 \mathrm{U}$ & Ikot Ekpene/Ugwuaji line 3 & 3.861 & 32.769 & 0.0301 & 99 \\
\hline 71 & $\mathrm{~K} 4 \mathrm{U}$ & Ikot Ekpene/Ugwuaji line 4 & 3.861 & 32.769 & 0.0301 & 99 \\
\hline 72 & E1Y & Gombe/Yola line & 9.360 & 79.440 & 0.0124 & 240 \\
\hline 73 & B3D & Benin/Asaba line & 5.343 & 45.347 & 0.0217 & 137 \\
\hline 74 & D3T & Asaba/Onitsha line & 0.799 & 6.785 & 0.1454 & 20.5 \\
\hline 75 & A1S & Makurdi/Jos line 1 & 10.374 & 88.046 & 0.0112 & 266 \\
\hline 76 & $\mathrm{~A} 2 \mathrm{~S}$ & Makurdi/Jos line 2 & 10.374 & 88.046 & 0.0112 & 266 \\
\hline 77 & $\mathrm{U} 1 \mathrm{~A}$ & Ugwuaji/Makurdi line 1 & 6.123 & 51.967 & 0.0189 & 157 \\
\hline 78 & $\mathrm{U} 2 \mathrm{~A}$ & Ugwuaji/Makurdi line 2 & 6.123 & 51.967 & 0.0189 & 157 \\
\hline 79 & $\mathrm{~J} 1 \mathrm{E}$ & Aja/Lekki 330kV line & 0.468 & 3.972 & 0.2483 & 12 \\
\hline 80 & J1B & Aja/Alagbon 330kV line & 1.014 & 8.606 & 0.1123 & 26 \\
\hline 81 & L7A & $\begin{array}{c}\text { Alaoji G/S / Alaoji T/S 330kV line } \\
1\end{array}$ & 0.195 & 1.655 & 0.5959 & 5 \\
\hline 82 & L8A & $\begin{array}{c}\text { Alaoji G/S / Alaoji T/S 330kV line } \\
2\end{array}$ & 0.195 & 1.655 & 0.5959 & 5 \\
\hline 83 & $\mathrm{D} 1 \mathrm{~K}$ & Odukpani/Ikot Ekpene line 1 & 1.443 & 12.247 & 0.0805 & 37 \\
\hline 84 & $\mathrm{D} 2 \mathrm{~K}$ & Odukpani/Ikot Ekpene line 2 & 1.443 & 12.247 & 0.0805 & 37 \\
\hline 85 & $\mathrm{~B} 5 \mathrm{~W}$ & Benin/Ikeja West & 11.032 & 84.840 & 0.0116 & 280 \\
\hline 86 & G1W & Delta/Aladja & 1.248 & 10.592 & 0.0931 & 32 \\
\hline 87 & E1D & Gombe/Damaturu & 6.240 & 52.960 & 0.0186 & 160 \\
\hline 88 & $\mathrm{D} 1 \mathrm{M}$ & Damaturu/Maidugiri & 10.140 & 86.060 & 0.0115 & 260 \\
\hline 89 & $\mathrm{Y} 1 \mathrm{G}$ & Yola/Jalingo & 5.460 & 46.340 & 0.0213 & 140 \\
\hline
\end{tabular}

\subsection{MATLAB PSAT Toolbox}

The system data is used in MATLAB code or modelled in PSAT in order to model the power system network under study. The capacity of these systems to handle the system analysis involved in this study cannot be overemphasized.

Using MATLAB scripts and PSAT software tool in MATLAB, the admittance matrix is estimated and saved. The load flow analysis is carried out using the Newton-Raphson method. Load flow data together with machine 
data is employed to model the dynamic performance of the system as a system of linear equations using small signal stability. Small disturbances represented as load changes are implemented sequentially on the system by working on the load data and executing a load flow calculation. The process is repeated until the system is ascertained to be unstable by modal analysis from the eigenvalue and eigenvector estimation procedure. Eventually, participation factors are then estimated which will signify the state's effects on each of the modes; consequently, depicting the most critical mode.

The power system steady state and dynamic model is reproduced in PSAT tool in a MATLAB software as shown in Figure 3 Then by using the transient stability module which is presented in Figure 4, plots of eigenvalues, participation factors, and other transient stability analysis are used to display load or bus transient performance. Predefined power system compensators models with their corresponding parameter inputs are used to ascertain locations by participation factor analysis to stabilize the system. The plots will also be used to show the impact of the power system compensators or SVCs on controlling the system and bringing the system out of instability.

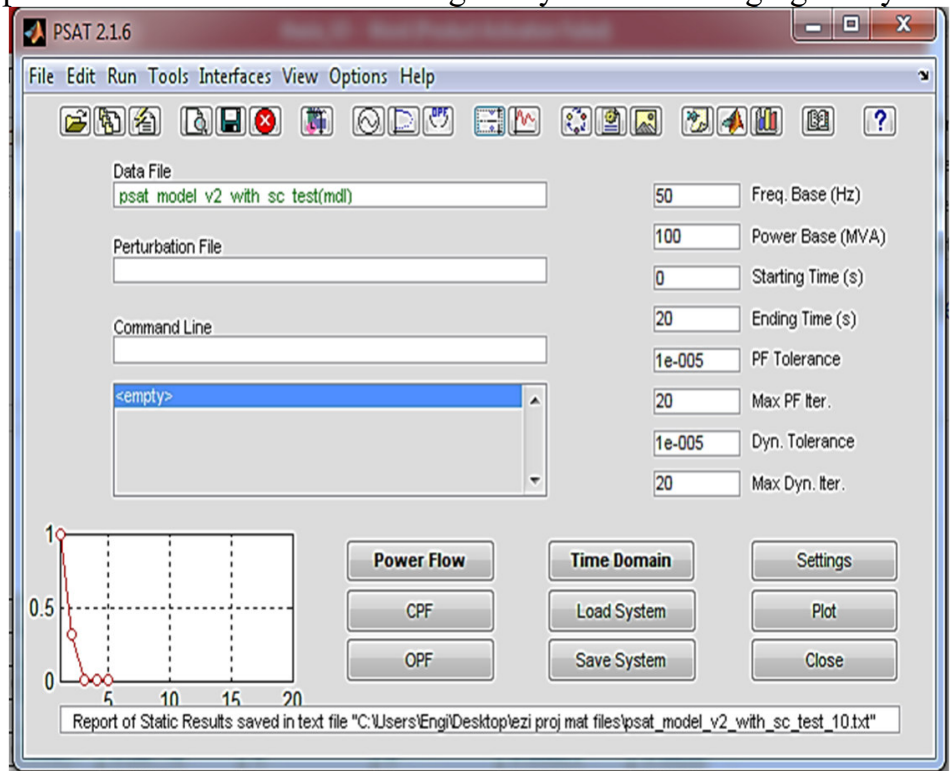

Figure 3 PSAT software tool interface

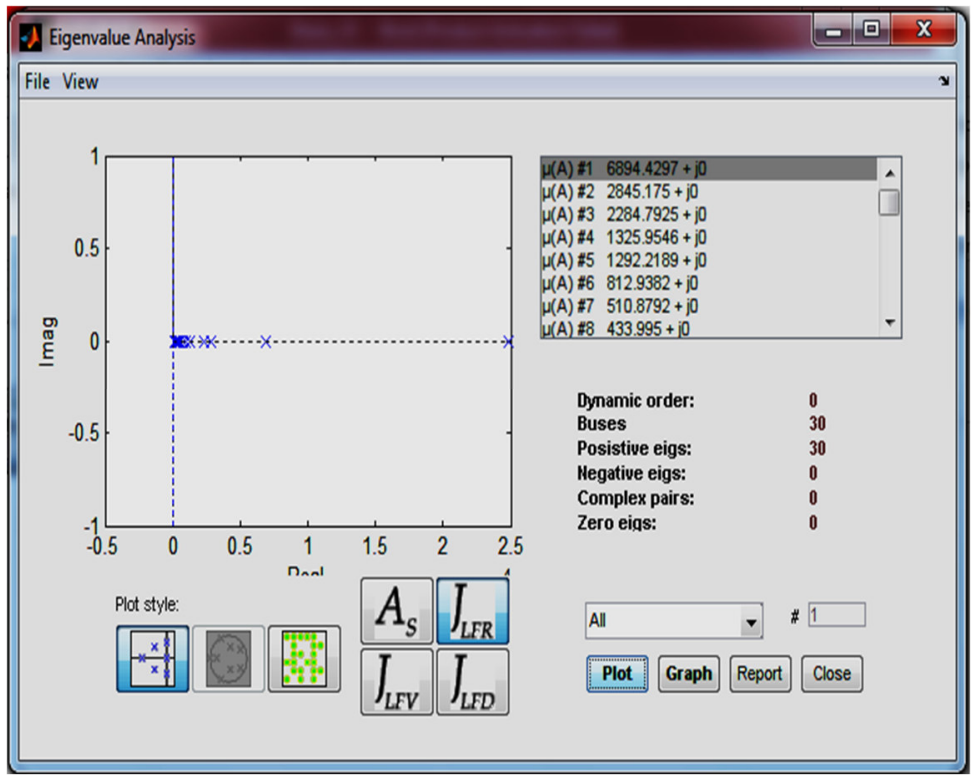

Figure 4 PSAT interface for plotting Eigenvalues, participation factors and other dynamic analysis

\section{RESULTS AND DISCUSSION}

As soon as the identification of the electrical system put under test is complete and the description of the simulation software codes, a system analysis and simulation will successively be carried out. The analysis and simulation process of the 48 Bus Nigerian power System Network contains several steps. The first step is to perform our test 
and analysis on the original 48 bus Nigerian power network without inserting any disturbance, and then identify the weak buses that are susceptible to instability. The next step is to simulate small disturbances by introducing load changes to the buses which are closer to instability compared to others and performing stability analysis on the network to see whether voltage instability or collapse will occur and subsequently introduce compensators at the critical buses and generation sources of these buses and monitor the improvement on the network. Then on this network load is added on the two weakest buses and analysis performed until the system become unstable then introduce compensators on this unstable system in order to ascertain the effectiveness of compensators in bringing the system out of instability caused by change in load at the weaker buses.

\subsection{Main Case Modal of the 48 bus 330kV Nigerian Network}

The various tests were performed on the model of the 48 bus 330KV Nigerian Network consisting of fifteen power generating systems. The power flow analysis of the model was carried out using PSAT in MATLAB Simulink environment. Table 3 shows the load flow results showing the voltage, phase angle, real power of the generators, reactive power of the generators, real power of load, and reactive power of load at the various buses.

Table 3: Main Case Model Power Flow Result of the three highest and three lowest voltage profile

\begin{tabular}{|l|l|l|l|l|l|l|}
\hline Bus & $\begin{array}{l}\text { V } \\
\text { (p.u.) }\end{array}$ & $\begin{array}{l}\text { Phase } \\
\text { (rad) }\end{array}$ & $\begin{array}{l}\text { P gen } \\
\text { (p.u.) }\end{array}$ & $\begin{array}{l}\text { Q gen } \\
\text { (p.u.) }\end{array}$ & $\begin{array}{l}\text { P load } \\
\text { (p.u.) }\end{array}$ & $\begin{array}{l}\text { Q load } \\
\text { (p.u.) }\end{array}$ \\
\hline Bus12 & 0.979 & 0.01882 & 2.9376 & -217.8541 & 1.56 & 0.65 \\
\hline Bus14 & 1.05 & 0.01813 & 24.081 & 112.6464 & 1.2776 & 0.63282 \\
\hline Bus23 & 1.05 & 0.02131 & 48.379 & 84.1565 & 0.04212 & 0.0351 \\
\hline Bus31 & 0.98871 & -0.00335 & 0 & 0 & 1.118 & 0.559 \\
\hline Bus34 & 0.98679 & -0.10691 & 0 & 0 & 0.7544 & 0.4715 \\
\hline Bus36 & 1.065 & 0.0022 & 0.004 & 107.9533 & 0 & 0 \\
\hline
\end{tabular}

Making reference to Table 3 and Figure 5, the voltages at the PQ buses all falls within the acceptable level of $\pm 5 \%$ with the bus value at bus 34 (Jalingo) having the lowest with PU voltages of 0.98679 which signify that the system voltages are relatively stable as required from the system when no disturbance is applied to the system. Utilizing the results for the load flow analysis, the eigenvalues were computed with their corresponding largest participation factor to identify the most significant state on that bus. A display of the table of the results and the required plot of the modes is shown in Table 4 and Figure 6.

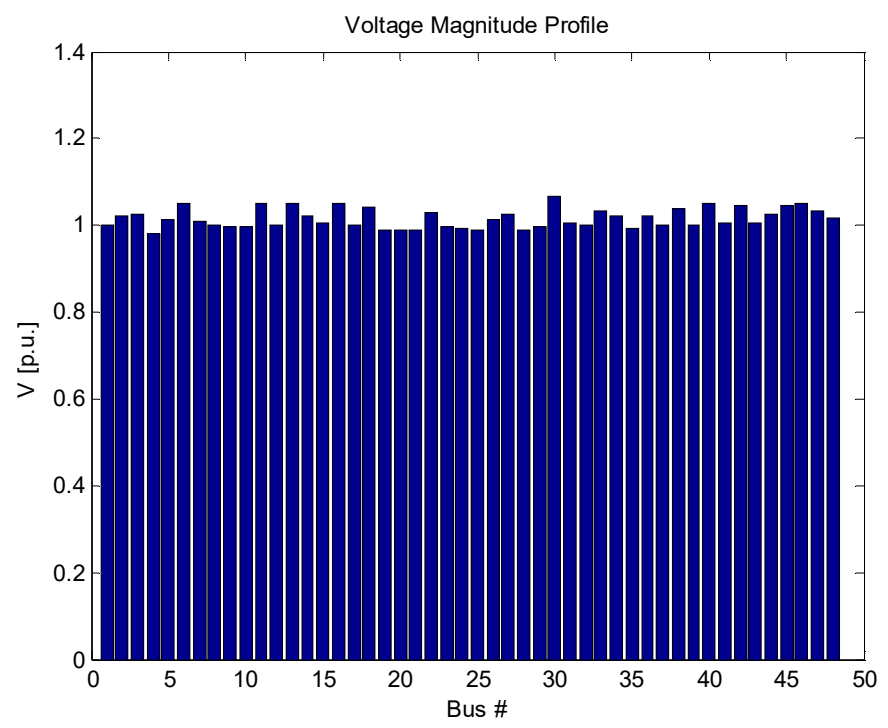

Figure 5: Angle profiles of all buses of the main case model of the 48 bus Nigerian power network system

Table 4 Three highest and three lowest Eigenvalues of the standard Jacobian matrix of the Main Case Modal of the 48 bus 330KV Nigerian Network

\begin{tabular}{|l|l|l|}
\hline Most Associated Bus & Real part & Imaginary Part \\
\hline Bus21 & 35015.2337 & 0 \\
\hline Bus9 & 23434.2254 & 0 \\
\hline Bus3 & 17919.4067 & 0 \\
\hline Bus34 & 6.2181 & 0 \\
\hline Bus28 & 165.0059 & 0 \\
\hline Bus25 & 727.8858 & 0 \\
\hline
\end{tabular}




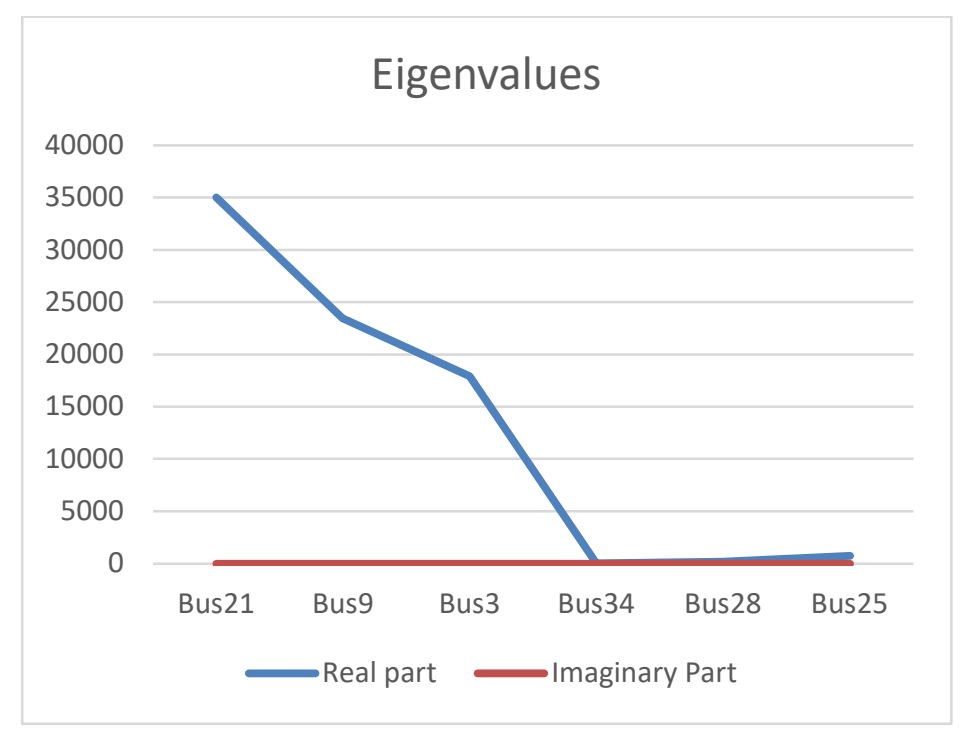

Figure 6: Three highest and three lowest eigenvalues of the main case model of the 48 bus Nigerian power network system

The observations from Table 4 indicate that all the eigenvalues are stable with the lowest obtained at Jalingo bus whose eigenvalue is 6.2181 is the most critical node. The participating factors computed for this weakest bus are shown in Table 5. Table 5 showed that bus 34 has the highest participation factor of 0.999 . The implication of this outcome indicates that the bus 34 offers the highest contribution to the voltage instability of the network.

Table 5: Participation factors at the smallest eigenvalue for the main case model

\begin{tabular}{|l|l|}
\hline Bus & Participation factor \\
\hline Bus1, Bus 10, Bus11, Bus12, Bus13 & \\
Bus15, Bus16 Bus17, Bus19, Bus2, & \\
Bus20, Bus1, Bus22, Bus23, Bus24, & \\
Bus25, Bus27, Bus29, Bus3, Bus28, & \\
Bus32, Bus33, Bus35, Bus36, Bus36, & 0 \\
Bus37, Bus38, Bus39, Bus4, Bus40, & \\
Bus41, Bus42, Bus43, Bus44, Bus45, & \\
Bus46, Bus47, Bus48, Bus5, Bus6, & \\
Bus7, Bus8, Bus9 & \\
\hline Bus18 & $1.00 \mathrm{E}-05$ \\
\hline Bus26 & $8.00 \mathrm{E}-05$ \\
\hline Bus27 & $8.00 \mathrm{E}-05$ \\
\hline Bus30 & $1.00 \mathrm{E}-05$ \\
\hline Bus31 & 0.00019 \\
\hline Bus34 & 0.99954 \\
\hline & \\
\hline
\end{tabular}

3.2 Main Case Modal of the 48 bus 330KV Nigerian Network with added load at the two weakest Buses The various tests were performed on the model of the 48 bus $330 \mathrm{KV}$ Nigerian Network consisting of fifteen power generating systems. The power flow analysis of the model was carried out using PSAT in MATLAB Simulink environment. Table 6 shows the load flow results showing the voltage, phase angle, real power of the generators, reactive power of the generators, real power of load, reactive power of load at the various buses.

Table 6: Power Flow Result of the Main Case Model with added load for three buses with the highest voltage profile and three buses with the lowest voltage profile

\begin{tabular}{|l|l|l|l|l|l|l|}
\hline Bus & $\begin{array}{l}\text { V } \\
\text { (p.u.) }\end{array}$ & $\begin{array}{l}\text { Phase } \\
\text { (rad) }\end{array}$ & $\begin{array}{l}\text { P gen } \\
\text { (p.u.) }\end{array}$ & $\begin{array}{l}\text { Q gen } \\
\text { (p.u.) }\end{array}$ & $\begin{array}{l}\text { P load } \\
\text { (p.u.) }\end{array}$ & $\begin{array}{l}\text { Q load } \\
\text { (p.u.) }\end{array}$ \\
\hline Bus28 & 0.63458 & -0.45581 & 0 & 0 & 1.8987 & 1.1867 \\
\hline Bus31 & 0.97051 & -0.03111 & 0 & 0 & 1.118 & 0.559 \\
\hline Bus34 & 0.97092 & -0.03029 & 0 & 0 & 0.7656 & 1.4201 \\
\hline Bus14 & 1.05 & 0.01303 & 24.081 & 112.6723 & 1.2776 & 0.63282 \\
\hline Bus20 & 1.05 & -0.00282 & 8.1526 & 50.6585 & 0.00602 & 0.0043 \\
\hline Bus23 & 1.05 & 0.01688 & 48.379 & 84.1684 & 0.04212 & 0.0351 \\
\hline
\end{tabular}

Making reference to Table 6 and Figure 7, the voltages at the PQ buses falls within the acceptable level of 
$\pm 5 \%$ except at bus 28 (Maidugiri) having the lowest with PU voltages of 0.63458 which signify that the system is experiencing voltage instability at bus 34 from the system when a disturbance is applied to the system's three weakest buses. Utilizing the results for the load flow analysis, the eigenvalues were computed with their corresponding largest participation factor to identify the most significant state on that bus. A display of the table of the results and the required plot of the modes is shown in Table 7 and Figure 8.

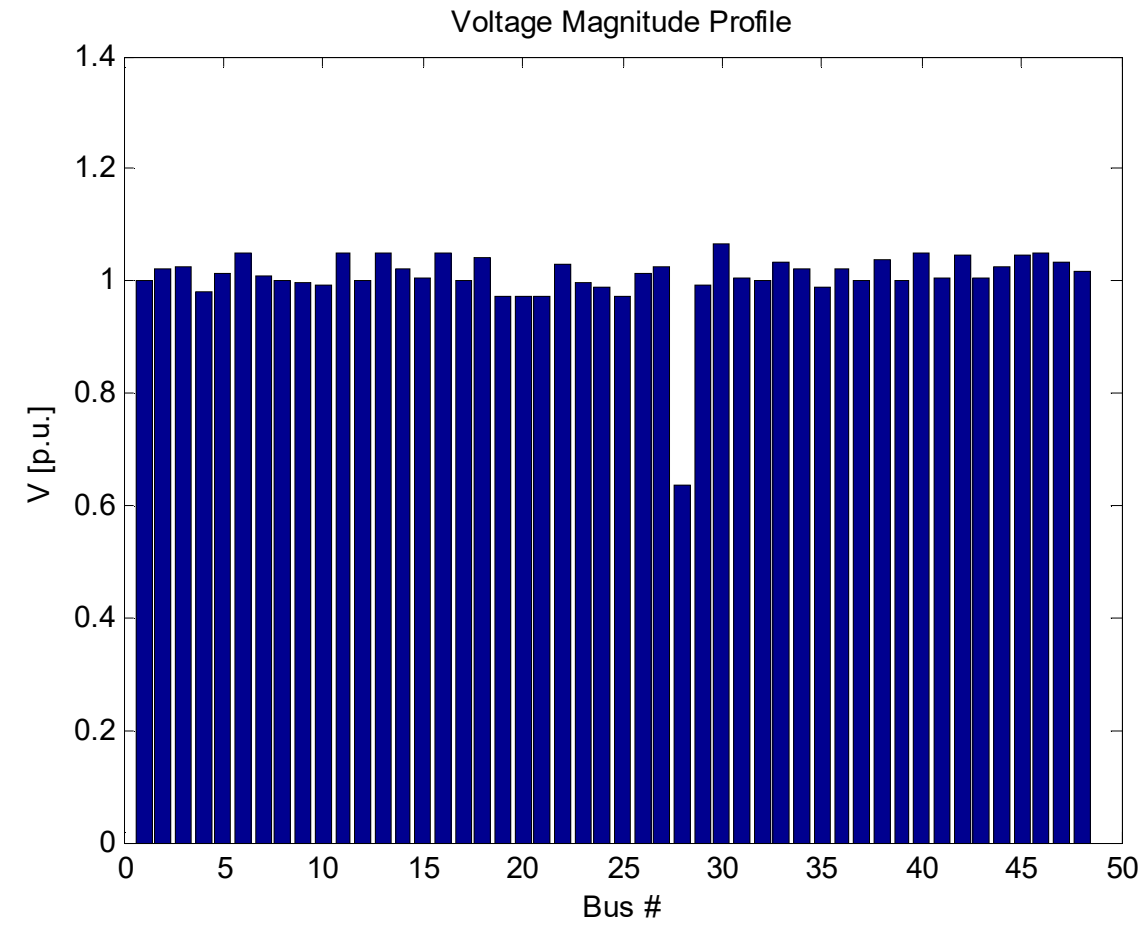

Figure 7: Angle profiles of all buses of the main case model of the 48 bus Nigerian power network system with added load at two weakest buses

Table 7 Three highest and three lowest Eigenvalues of the standard Jacobian matrix of the Main Case Modal of the 48 bus 330kV Nigerian Network with added load disturbances at weakest buses

\begin{tabular}{|l|l|l|}
\hline Most Associated Bus & Real part & Imaginary Part \\
\hline Bus21 & 35015.7528 & 0 \\
\hline Bus9 & 23433.9648 & 0 \\
\hline Bus3 & 17889.3353 & 0 \\
\hline Bus34 & 1.4423 & 0 \\
\hline Bus28 & 160.4958 & 0 \\
\hline Bus25 & 727.8858 & 0 \\
\hline
\end{tabular}




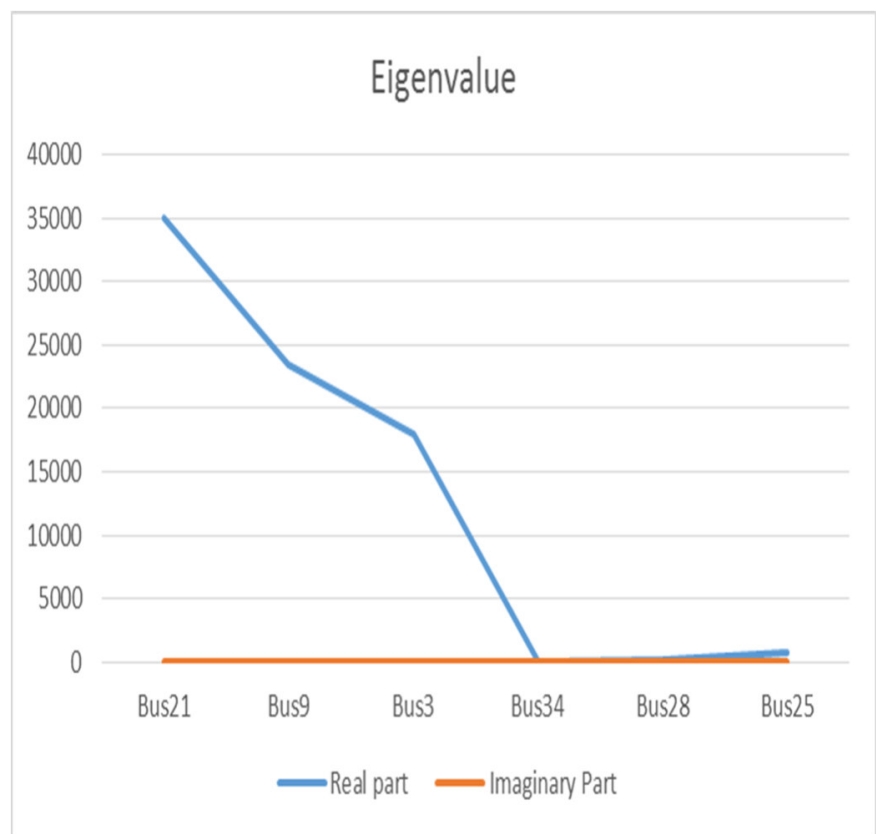

Figure 8: Eigenvalues of all buses for the main case model of the 48 bus Nigerian power network system with added load disturbances at weakest buses

For second case of the model with added load at the three weakest buses identified from the first model from Figure 8 all the eigenvalues are positive, this is an indication that the system is stable but has a less stability profile than the main case observed from the characteristics of the eigenvalues.

Referring to Table 7 and Figure 8, observation made shows that the system is stable but tending towards instability since all the mode $\lambda$ is located on the left half of the imaginary plane, but the smallest eigenvalue experienced a drop from 6.2181 in Table 4 to 1.4423 in Table 7 when compared to the main model without load added at the weakest buses. Hence the system will move to a state of collapse with the addition of more constant PQ loads at the weak bus and the instability will continue to increase with addition of loads to this bus. Further increase of load at the weak buses can lead to power system collapse. The participating factors computed for this identified critical mode are shown in Table 8.

Table 8: Participation factors at the smallest eigenvalue for the main case model with added loads at weak buses

\begin{tabular}{|l|l|}
\hline Bus & Participation factor \\
\hline Bus1, Bus10, Bus11, Bus12, Bus13, Bus14, & \\
Bus15, Bus16, Bus17, Bus19, Bus2, Bus20, & \\
Bus21, Bus22, Bus23, Bus24, Bus25, Bus28, & \\
Bus29, Bus3, Bus32, Bus33, Bus35, Bus36, & 0 \\
Bus37, Bus38, Bus39, Bus4, Bus40, Bus41, & \\
Bus42, Bus43, Bus44, Bus45, Bus46, Bus47, & \\
Bus48, Bus5, Bus6, Bus7, Bus8, Bus9, & \\
\hline Bus18 & $1.00 \mathrm{E}-05$ \\
\hline Bus26 & $8.00 \mathrm{E}-05$ \\
\hline Bus27 & $8.00 \mathrm{E}-05$ \\
\hline Bus30 & $1.00 \mathrm{E}-05$ \\
\hline Bus31 & 0.00019 \\
\hline Bus34 & 0.99954 \\
\hline & \\
\hline
\end{tabular}

3.3 Effect of using Compensators on the Model of the 48 bus 330KV Nigerian Network with added load Various tests were performed on the model of the 48 bus $330 \mathrm{kV}$ Nigerian Network with added load at critical points and the effect of the application of compensators on the network observed. The power flow analysis of the model was carried out using PSAT in MATLAB Simulink environment. Table 9 and shows the load flow results showing the voltage, phase angle, real power of the generators, reactive power of the generators, real power of load, reactive power of load at the various buses. 
Table 9: Power Flow Result of the Main Case Model with added load using compensators for three buses with the highest voltage profile and three buses with the lowest voltage profile

\begin{tabular}{|l|l|l|l|l|l|l|}
\hline Bus & $\begin{array}{l}\text { V } \\
\text { (p.u.) }\end{array}$ & $\begin{array}{l}\text { Phase } \\
\text { (rad) }\end{array}$ & $\begin{array}{l}\text { P gen } \\
\text { (p.u.) }\end{array}$ & $\begin{array}{l}\text { Q gen } \\
\text { (p.u.) }\end{array}$ & $\begin{array}{l}\text { P load } \\
\text { (p.u.) }\end{array}$ & $\begin{array}{l}\text { Q load } \\
\text { (p.u.) }\end{array}$ \\
\hline Bus12 & 0.979 & 0.01344 & 2.9376 & -217.9362 & 1.56 & 0.65 \\
\hline Bus31 & 0.98696 & -0.03523 & 0 & 0 & 1.118 & 0.559 \\
\hline Bus27 & 0.98803 & -0.03251 & 0 & 0 & 23.1936 & 12.3216 \\
\hline Bus14 & 1.05 & 0.01275 & 24.081 & 112.6143 & 1.2776 & 0.63282 \\
\hline Bus20 & 1.05 & -0.00326 & 8.1526 & 50.6589 & 0.00602 & 0.0043 \\
\hline Bus23 & 1.05 & 0.01684 & 48.379 & 84.099 & 0.04212 & 0.0351 \\
\hline
\end{tabular}

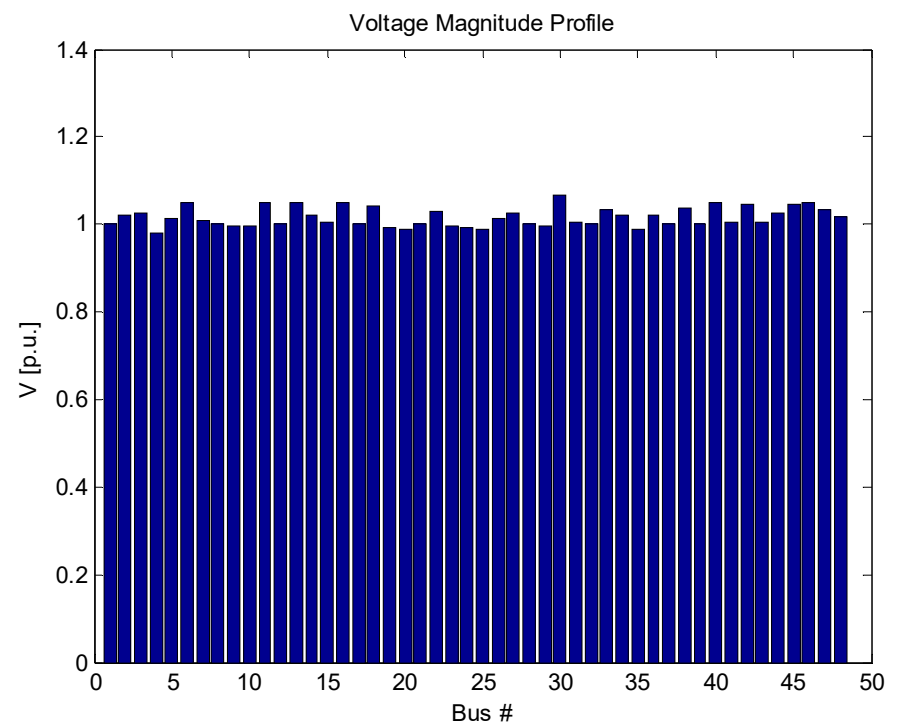

Figure 9: Angle profiles of all buses of the main case model of the 48 bus Nigerian power network system with added load at two weakest buses

Making reference to Table 9 and Figure 9, the voltages at the PQ buses falls within the acceptable level of $\pm 5 \%$ at all the buses with bus 12 now having the lowest per unit voltage profile of 0.979 which signify that the compensators have improved the voltage stability compared to the system when a disturbance is applied to the system's three weakest buses. Utilizing the results for the load flow analysis, the eigenvalues were computed with their corresponding largest participation factor to identify the most significant state on that bus. A display of the table of the results and the required plot of the modes is shown in Table 10 and Figure 10. From Table 10 all the eigenvalues are positive this is an indication that the system is stable.

Table 10 Three highest and three lowest Eigenvalues of the standard Jacobian matrix of the Main Case Modal of the 48 bus 330KV Nigerian Network with added load and application of compensators

\begin{tabular}{|l|l|l|}
\hline Most Associated Bus & Real part & Imaginary Part \\
\hline Bus21 & 35015.7919 & 0 \\
\hline Bus9 & 23434.7444 & 0 \\
\hline Bus3 & 17915.1652 & 0 \\
\hline Bus31 & 488.7831 & 0 \\
\hline Bus40 & 972.7492 & 0 \\
\hline Bus25 & 727.8858 & 0 \\
\hline
\end{tabular}




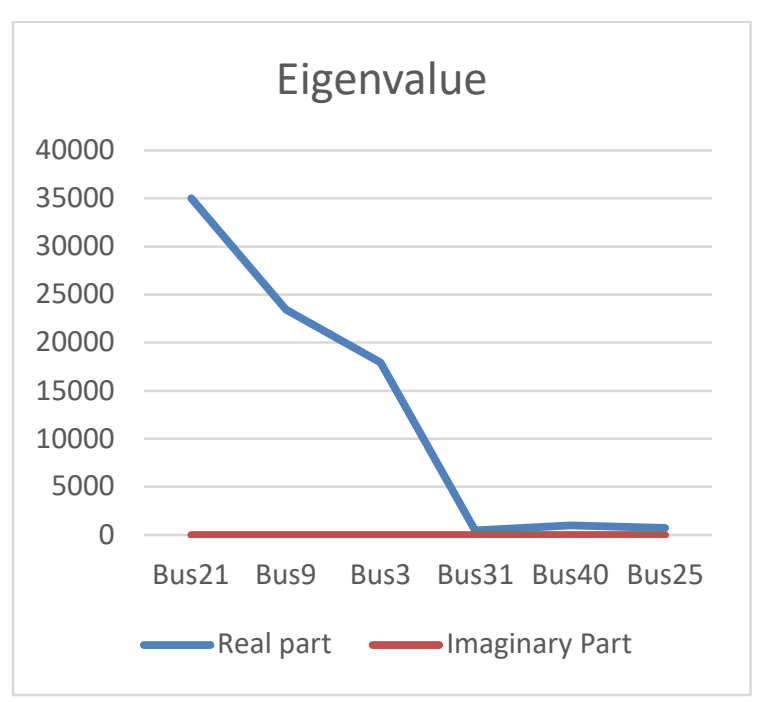

Figure 10: Eigenvalues of all buses for the main case model of the 48 bus Nigerian power network system with added load disturbances at weakest buses

Referring to Table 10 and Figure 10, observation made shows that the system is stable but tending toward instability since all the mode $\lambda$ is located on the left half of the imaginary plane, but the smallest eigenvalue experienced an improvement from 1.4423 in Table 7 to 488.7831 in Table 10 when compare to the main model without added load at weakest buses. Hence the system disturbances caused by change in PQ loads at the weak bus cause instability but placing compensators on sources linked with the weak buses can minimize the effect of these disturbances. The participating factors computed for this identified critical mode are shown in Table 11.

Table 11: Participation factors at the smallest eigenvalue for the main case model

\begin{tabular}{|l|l|}
\hline Bus & Participation factor \\
\hline Bus1, Bus10, Bus11, Bus12, Bus13, Bus14, Bus15, & \\
Bus19, Bus2, Bus20, Bus21, Bus23, Bus24, Bus25, & \\
Bus28, Bus29, Bus3, Bus32, Bus33, Bus36, Bus37, & 0 \\
Bus38, Bus39, Bus4, Bus41, Bus42, Bus43, Bus44, & \\
Bus45, Bus47, Bus5, Bus6, Bus7, Bus8,Bus34 & \\
\hline Bus3 & 0.00312 \\
\hline Bus9 & $1 \mathrm{e}-005$ \\
\hline Bus16 & 0.00571 \\
\hline Bus17 & 0.01148 \\
\hline Bus18 & 0.04402 \\
\hline Buss22 & 0.00027 \\
\hline Bus26 & 0.08038 \\
\hline Bus27 & 0.22669 \\
\hline Bus30 & 0.07755 \\
\hline Bus31 & 0.49694 \\
\hline Bus35 & 0.01635 \\
\hline Bus40 & 0.03686 \\
\hline Bus46 & $2 \mathrm{e}-005$ \\
\hline Bus48 & 0.00059 \\
\hline
\end{tabular}

\section{CONCLUSION}

Application of Modal Analysis on the 48 bus 330KV Nigerian Network has been explored and tested using PSAT MATLAB Toolbox. The Modal/Eigenvalue analysis technique was used to investigate the stability of the 48-bus Nigerian power network system. The method calculates the smallest eigenvalue and all the associated eigenvectors of the reduced Jacobian matrix using the steady state mode. The magnitude of the smallest eigenvalue gives us a measure of how close the system is to the voltage instability. Then, the participation factor was used to identify the weakest link or point or bus to the system associated to the minimum eigenvalues.

The 48-bus Nigerian network was simulated under changing loads condition until the system was driven to point of instability and Modal/Eigenvalue analysis was performed on the system under each of these conditions.

Results obtained in this study proved that compensators were able to drastically improve the voltage stability profile of the 48 bus Nigerian network and even rescue the system at the event of voltage instability especially 
ones caused by change in loads.

\section{REFERENCES}

1. Transmission Company of Nigerian National Control Centre, Abuja (2018). "Generation and Transmission Grid Operations", Annual Technical Report for 2018, TCN publisher.

2. Samuel, I. A., Katende, J., Daramola, S. A., \& Awelewa, A. A. (2014), (a). Review of System Collapse Incidences on the 330-kV Nigerian National Grid. International Journal of Engineering Science Invention, 3, 55-59.

3. Enemuoh, F. O. (2012) Simulation Modelling of Voltage Stability of an Interconnected Electric Power System Network. PhD Thesis, Department of Electrical Engineering University of Nigeria, Nsukka.

4. Enemuoh F. O., Onuegbu J. C. and Dr. Anazia E. A. (2013). Modal Based Analysis and Evaluation of Voltage Stability of Bulk Power System. International Journal of Engineering Research and Development, 6, 71-79.

5. Ephraim N. C. O. (2007). Voltage Stability Evaluation for System Collapse Improvement in Nigeria Electric Power System using Modal Technique. PhD Thesis, Department of Electrical and Electronic Engineering, Federal University of Technology Owerri, 174p.

6. Jan, V. (2013). Performance of Steady-State Voltage Stability Analysis in MATLAB Environment University of West Bohemia in Pilsen, Regional Innovation Centre of Electrical Engineering, Pilsen, Czech Republic, Transactions on Electrical Engineering, 2, 82-87

7. Mohd A. (2014). Adaptive Protection and Control for Wide Area Blackout Prevention. PhD Thesis in Electrical Engineering, Imperial College London, 150p.

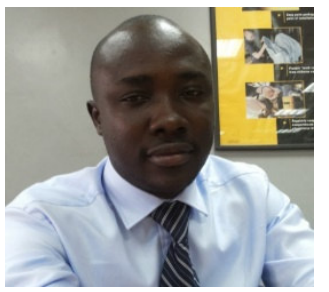

EZEKIEL NNAMERE ANEKE (MNSE, COREN, MIEEE), was born in May 14th in Enugu State, Nigeria. He received B.Eng in Electrical and Electronic Engineering from Enugu State University of Science and Technology in 2008; he also received his M.Eng in Electrical and Electronic Engineering from same University in 2014. He is currently a Ph.D student in the Electrical and Electronics Engineering department of Enugu State University of Science and Technology. His major field of study is electrical power systems and machines.

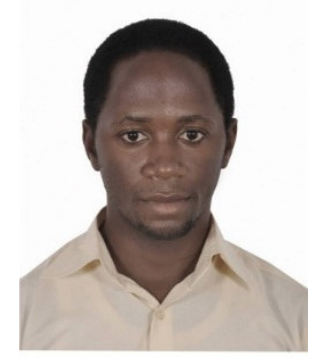

Engla Anzaku is an innovator in the field of electrical and electronics engineering.

Engla received his bachelors of electrical and electronics engineering at Abubakar Tafawa Balewa University, Bauchi, Nigeria. He then proceeded to study masters of power system engineering in Federal University of Agriculture, Makurdi, Nigeria. Engla believe in research and technological advancement. After graduation from first degree Engla started working at Nasarawa State Polytechnic as a part-time lecturer in the department of mechatronics and served as an instructor for about two years. After that, had an opportunity to work in Voice of Nigeria Engineering Department which is still his present place of work.

In addition to working at Voice of Nigeria, Engla is deeply involved in solar energy system solutions and mechatronics. 